\title{
Power Quality versus Electromagnetic Compatibility in Adjustable Speed Drives
}

\author{
M. I. Buzdugan, H. Bălan \\ ${ }^{1}$ Department of Electrical Engineering \\ Technical University of Cluj-Napoca, \\ 28, Memorandumului str, Cluj-Napoca (Romania), \\ Phone number: +40 744560 833, Fax number: +40 264410 179, \\ e-mail: mircea.buzdugan@insta.utcluj.ro, \\ horia.balan@eps.utcluj.ro
}

\begin{abstract}
The present approach is intended to bring off a tighter relationship between power quality and electromagnetic interference issues in electric drives. The authors opinion is that if harmonics are widely covered in power quality literature, higher frequency perturbations that inherently appear due to power electronic devices are generally neglected.
\end{abstract}

The concept is developed for adjustable speed drives of wellhead induction motors from a large oil onshore extraction field. Due to the variable loads and the heavy duty cycles of the motors, the harmonics problem needed to be solved in the same time with the conducted electromagnetic perturbations.

The harmonic content of the currents together with the conducted electromagnetic interferences were analyzed, mitigation countermeasures being proposed and applied.

\section{Key words}

Harmonics, conducted interference, ASD - adjustable speed drives, 6-pulse inverter, passive filters.

\section{Introduction}

In the last years, the interest in power quality became more and more important for suppliers, manufacturers and customers.

Suppliers are interested in the quality of their service, manufacturers have to build equipments compliant to a sum of standards and regulations with respect to power quality and finally customers want in their turn to have comfort and a quite life in using electrically powered products.

Unfortunately, high speed semiconductor devices with fast switching capability and the emerging digital era in control and signal processing became the main enemies of electrical power quality.

On one hand, equipments need power quality, being less tolerant of voltage and current disturbances but on the other they represent the main source of electromagnetic perturbations in power lines.

In literature one can find plenty and sometimes conflicting definitions of power quality, related more or less to the performance of equipment or to the possibility of measuring and quantifying the performance of the power system (see the IEEE Standards and the IEC and EN Standards). For instance the Council of European Energy Regulators-Working Group on Quality of Electricity Supply speaks about voltage quality and includes the following disturbances: "frequency, voltage magnitude and its variation, voltage dips, temporary and transient overvoltages, and harmonic distortion", without mentioning explicitly "current quality", which probably is implicitly considered where it affects the voltage quality [1]. The point of view here is again that current quality is only a concern only if it affects the voltage quality. This difficulty of distinguishing between voltage and current disturbances is one of the reasons the term power quality is generally used. The term voltage quality is reserved for cases where only the voltage at a certain location is considered. The term current quality is generally used to describe the performance of power electronic converters connected to the power network [2].

In the authors' opinion, there is no power quality in the presence of electromagnetic interference, i.e. the process by which disruptive electromagnetic energy is transmitted from one electronic device to another via radiated or conducted paths (or both) [3]. In this respect, every disturbance is a power quality issue, even the IEC and EN standards distinguish between an (electromagnetic) disturbance and (electromagnetic) interference: "A disturbance is a phenomenon which may degrade the performance of a device, equipment or system, or adversely affect living or inert matter" [4]. In power quality terms, any deviation from the ideal voltage or current can be considered as a disturbance. Interference is much stricter defined, being the actual degradation of a device, equipment or system caused by an electromagnetic disturbance. 
Along with a large variety of nonlinear loads (discharge lamps, uninterruptible power supplies, electronic power supplies, etc.), adjustable-speed drives represent an important source of power quality disturbances, waveform distortion, being also sensitive to certain types of power quality disturbances.

Power electronic offers a plenty of advantages in efficiency and controllability. However, they draw nonsinusoidal currents from AC power systems, these currents react with system impedances creating voltage harmonics and, in some cases, resonance in distribution feeders as power electronic loads continue to proliferate.

In literature, power quality associated with variable speed drives means mainly voltage dips, supply interruptions and harmonic distortion that have negative effects on almost all the components of the electrical system, by causing new dielectric, thermal and mechanical stresses [5-9].

Harmonic components can significantly impact motors, especially through voltage distortion, directly related with harmonic fluxes within the motor. Harmonic fluxes do not contribute to motor torque, rotating at a different frequency than the rotor and inducing high-frequency currents in the rotor, being similar to that of negativesequence currents at fundamental frequency, the well known effect being the motors' overheating, when the voltage distortion (THDU) exceeds the limit of $8 \%$ imposed by the standard EN 61000-4-7.

Another effect due to the presence of harmonics is torsional oscillation. The $5^{\text {th }}$ harmonic is a negative sequence harmonic, and the resulting magnetic field revolves in a direction opposite to that of the fundamental field at a speed five times that of the fundamental field. The $7^{\text {th }}$ harmonic is a positive sequence harmonic, with a resulting magnetic field revolving in the same direction as the fundamental field at a speed of seven times the fundamental. The resulting effect is a magnetic field revolving at a speed of six times the speed of the rotor. The resulting interaction between the magnetic fields and the currents induced in the rotor produces torsional oscillations of the motor. Obviously, severe damage to the motor can occur if the frequency of the oscillation matches the natural frequency of the motor.

Harmonic currents do really affect all the components of a power system leading to its inefficiency. Thus, on undersized conductors or cables, harmonic currents cause a more pronounced "skin effect", increasing with frequency, capacitors can be affected by heat rise increases due to power loss and reduced life operation time, fuses and circuit breakers can cause false or spurious operations and trips, transformers and generators may have increased iron and copper losses or eddy currents due to stray flux losses, which determines excessive overheating in their windings.

The high frequencies in the switching and transient spikes are also induced into the rotor and build up a voltage potential between the rotor and stator, which is dissipated by arcing through the ball bearings, ruining in time the finish in the bearing races and causing premature failure.

Electric drives can also be affected by harmonic currents by misoperation due to multiple zero crossings and failure of the commutation circuits.

Today, both low and high-power equipments are more and more powered by power electronic converters, generating broad spectrum of distortion, which is obviously rising. However, high-frequency transients do occasionally receive attention as causes of equipment malfunction and are generally not well covered in the power quality literature. For example, even the European standard EN 50160, [10] gives useful information for variations (voltage fluctuations, dips, interruptions, etc.) which are regulated disturbances, but nothing for events (fast transients) which are not.

The present approach is intended to widen investigation area of power quality for power converters, considering that power quality is included in the larger concept of electromagnetic compatibility. The concept will be illustrated by a case study performed in an onshore oil field, where the authors performed an energy audit.

The oil field is supplied through two medium voltage overhead lines of $20 \mathrm{kV}$, sixteen transformer substations $20 / 0.5 \mathrm{kV}$ and a low voltage distribution grid supplying the production wellheads, the water injection pumps, the gas injection compressors and the crude pumps. In addition power supply is necessary for utilities (HVAC with cogeneration, firefighting systems, potable water, lighting, etc.). The complexity of the power system supplying the oil field is obvious, thus an energy audit intended to set technical and organizational measures in order to increase energy efficiency were more than mandatory.

Further in the paper are presented power quality and conducted electromagnetic interferences problems detected in the adjustable speed drives (ASD) of wellhead induction motors together with some improving countermeasures.

\section{Measurements and Discussions}

The wellhead induction motors are supplied by 6-pulse, pulse-width modulation (PWM) drive with insulated gate bipolar transistors (IGBTs), the most common type used in such an environment (Fig. 1) [11-13].

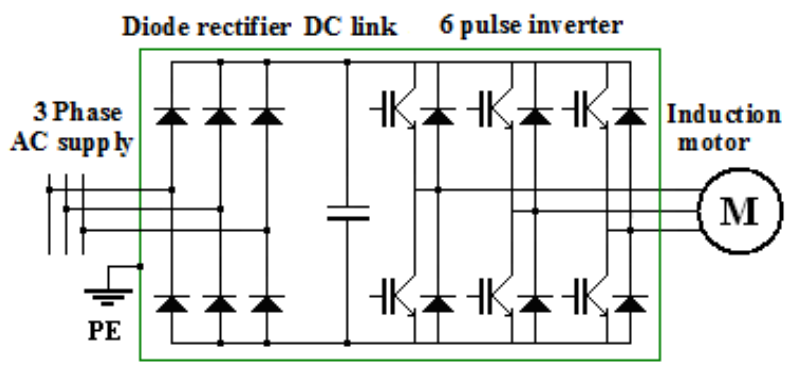

Fig. 1. 6-pulse converter 
The converter's part of the ASD dominates the interaction of the drive with its source system. Therefore, its operation determines the extent of the harmonics introduced into the electrical distribution system to which it is connected.

Measurements were performed using the Power \& Quality Analyser, Qualistar Plus C.A. 8335 (Chauvin Arnoux) which is a recorder and analyzer for measurements on electrical power networks offering all the necessary functions with demanding specifications usually reserved for top-of-the-range laboratory instruments [14].

The instrument is seeking all the functions of an electrical network analyzer in a portable, battery-powered instrument. Between its main features it can be recalled:

- Real-time display of wave forms (4 voltages and 4 currents)

- RMS voltage and currents per half-period

- Automatic recognition of the different types of current sensors

- Integration of all the DC components

- Measurement, calculation and display of the harmonics up to the 50th order, along with the phase information

- Calculation of Total Harmonic Distortion (THD)

- Capture of transients per sample (1/256th of a period)

- Display of phasor diagram (in practice the use of phasor diagrams is an effective way of ensuring that the right connections are set up for reliable measurements).

- Measurement of VA, W and VAr power values (total and per phase)

- Measurement of VAh, Wh and VArh energy values (total and per phase)

- Calculation of the K-Factor (indicates the amount of heat produced by sinusoidal currents compared with the same rms value of a pure sine current; a K-Factor of 1.0 corresponds to a linear load with no harmonics)

- Calculation of the $\cos \varphi$ displacement power factor (DPF) and the power factor (PF)

- Capture of up to 300 transients

- Flicker calculation

- Unbalance calculation (current and voltage)

- Monitoring of the electrical network with setting of alarms

- Back-up and recording of screenshots (image and data)

- Software for data recovery and real-time communication with a PC

- Recording and export onto PC.

In Fig. 1 is presented a set of recorded values concerning the main electrical parameters of the supply grid.

\begin{tabular}{|c|c|c|c|c|c|c|c|c|c|c|}
\hline \multicolumn{3}{|c|}{\begin{tabular}{|l|l|} 
Print & Create DataView Report \\
\end{tabular}} & \multicolumn{8}{|c|}{\begin{tabular}{l|l|} 
Create Spreadsheet & Recorded Parameters \\
\end{tabular}} \\
\hline \multirow{2}{*}{$\begin{array}{l}\text { OWaveform } \\
\text { Date }\end{array}$} & \multirow{2}{*}{$\begin{array}{l}\text { Harmonic } \\
\text { Time }\end{array}$} & \multirow{2}{*}{$\begin{array}{l}\text { (1) List } \\
\text { Channel }\end{array}$} & \multicolumn{2}{|c|}{ MINMAX } & \multicolumn{2}{|l|}{ OPower } & \multicolumn{2}{|c|}{ O Energy } & \multicolumn{2}{|c|}{ O Phasor } \\
\hline & & & unb\% & THD & CF & Pst & $\mathrm{KF}$ & DC & DF & RMS \\
\hline \multirow[t]{9}{*}{12.12 .2011} & $14: 05: 42.030$ & v1 & $100,0 \%$ & $1,2 \%$ & 1,48 & 0,93 & & 0,8 & 1,2 & 305 \\
\hline & & V2 & & $1,4 \%$ & 1,49 & 1,32 & & $-0,2$ & 1,4 & 304,3 \\
\hline & & v3 & & $1,1 \%$ & 1,49 & 0,91 & & $-0,6$ & 1,1 & 303,9 \\
\hline & & A1 & $100,0 \%$ & $44,8 \%$ & 1,77 & & 7,94 & & 40,9 & 6,48 \\
\hline & & A2 & & $48,6 \%$ & 1,78 & & 9,16 & & 43,7 & 6,24 \\
\hline & & A3 & & $53,5 \%$ & 1,83 & & 10,5 & & 47,2 & 6,07 \\
\hline & & U1 & & $1,1 \%$ & 1,41 & & & 0,9 & 1,1 & 528 \\
\hline & & U2 & & $1,0 \%$ & 1,4 & & & 0,5 & 1,0 & 526,2 \\
\hline & & U3 & & $1,0 \%$ & 1,41 & & & $-1,4$ & 1,0 & 526,8 \\
\hline
\end{tabular}

Fig.2. Main electrical parameters recorded by the power analyzer
From Fig. 2 it can be seen that the THD's of the supply voltages are around $1.0 \%$, which justify the shape almost sinusoidal of the voltage waves, depicted in Fig. 2. The almost pure sine form is affected only by the PWM frequency, as one can see from the shape of the wave.

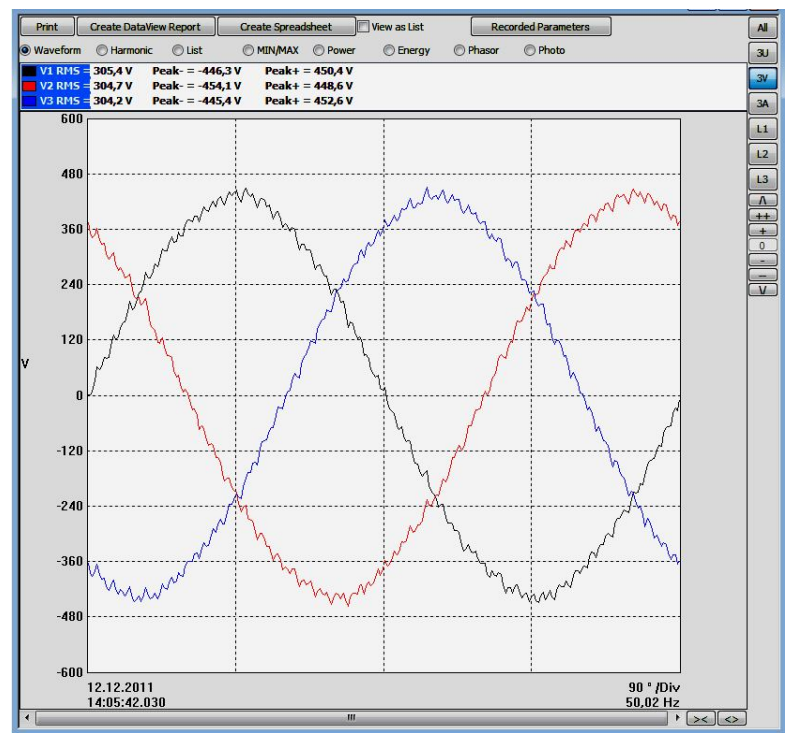

Fig.1. Supply voltages of the ASD

The high value of K-Factor on the supply lines, associated to the excessive THD's of the currents drawn from the lines and the poor displacement power factor, indicate a power quality issue regarding currents distortion and harmonic content. Pst (the short-term flicker) determined by the supply voltage has no importance in the analyzed environment.

In Fig. 3 are presented the distorted waveforms of the current drawn from line 2 , indicating also a lagging phase angle of $67^{\circ}$.

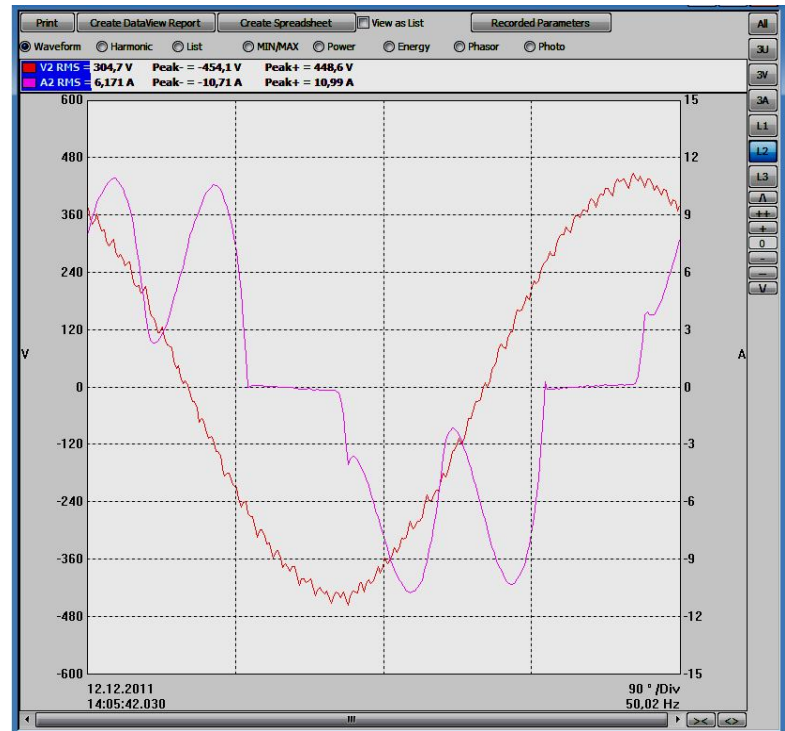

Fig. 3. Voltage supply and current value drawn by line 2 of the ASD

Fig. 4 depicts the FFT chart of the supply voltage and current drawn by line 2 . One can easily notice that the 
harmonic content of the supply voltage (dark red) is negligible.

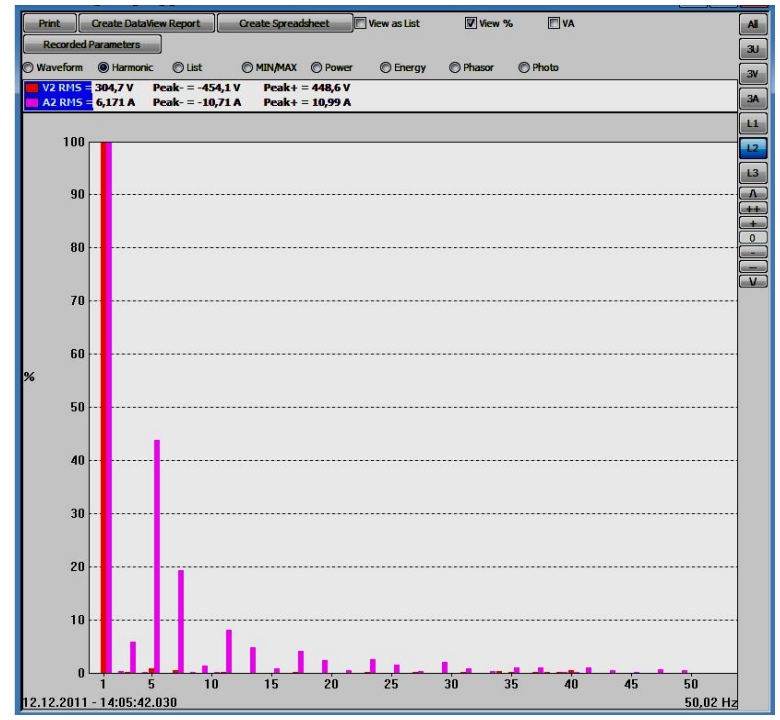

Fig. 4. THVD and TDID in line 2 of the ASD

The mathematical representation of harmonics is widely covered in literature [6-9]. Leaving the mathematical aspects aside and looking at the graph (Fig. 5.), a noteworthy fact is that such an AC drive does not produce a third harmonic component. The $5^{\text {th }}, 7^{\text {th }}$ and somehow the $11^{\text {th }}$ and the $13^{\text {th }}$ order harmonic components are significant. Starting from this, one can conclude that it is a simple issue of harmonic filtering. But, due to high frequency transients, determined especially by the PWM frequency, the parasitic capacitance to the ground plane and the coupling of adjacent cables, the AC drive creates a certain level of electromagnetic interference to the mains power network and the surrounding electrical devices.

The conducted interferences were measured using the spectrum analyzer HM5014 (Hameg Instruments) [15] an instrument based on the high frequency characteristics. The most important features of the spectrum analyzer are: the usable frequency range, from $150 \mathrm{kHz}$ to above 30 $\mathrm{MHz}$, the available resolution bandwidths of $9 \mathrm{kHz}, 120$ $\mathrm{kHz}$ and $400 \mathrm{kHz}$, the processor-controlled operation and a digital signal display which works in real-time and is resolved with up to 4,000 points over the entire screen.

In Fig. 5 is depicted the peak value of the conducted perturbation spectrum, ranging from $100 \mathrm{kHz}$ to $30 \mathrm{MHz}$. It can be seen that in the range until $10 \mathrm{MHz}$, the recorded values exceed the prescriptions of the standard EN 61800$3: 2004 / \mathrm{A} 1$ [16].

The situation is better revealed in the same characteristics, depicted in a logarithmic scale (Fig. 6). One can see that the peak values of the conducted electromagnetic perturbations are exceeding the average (blue line) and the peak (red line) limits from the standard (the peak value being nearly $20 \mathrm{~dB} \mu \mathrm{V}$ higher).

In order to improve energy efficiency, it became obvious that a few countermeasures of power quality with respect to harmonics and conducted interferences were mandatory. It is well-known that in such cases filtering methods represent the best solution.

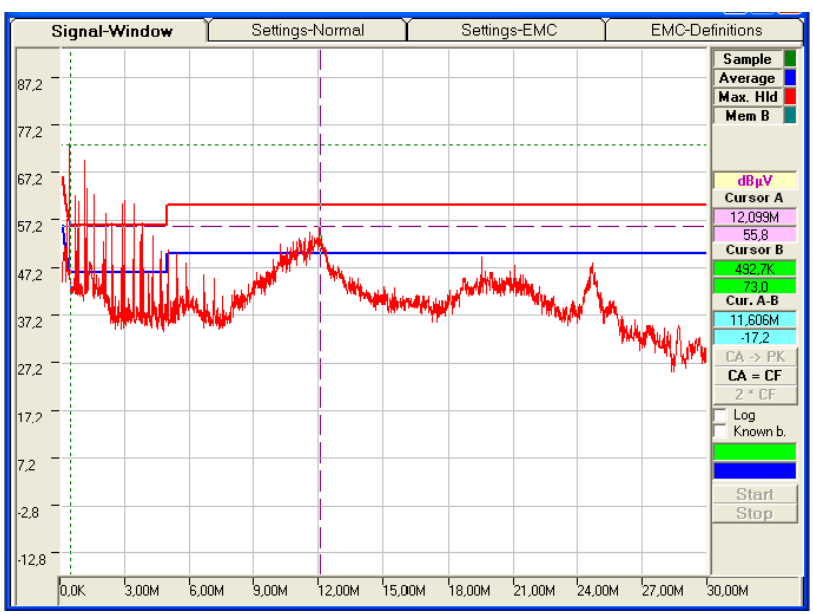

Fig. 5. Conducted interference generated by the ASD

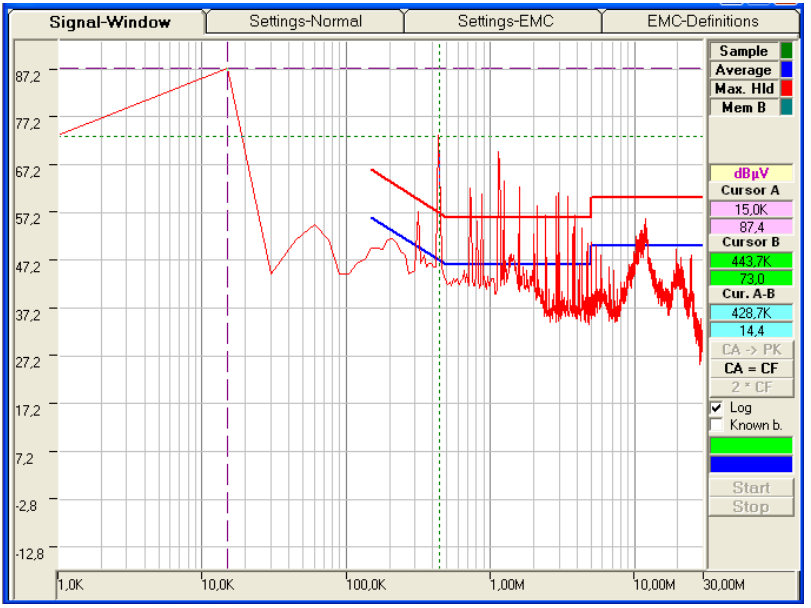

Fig. 6. Conducted interference generated by the ASD (logarithmic scale)

\section{Harmonics and Conducted Interferences Mitigation}

Active filters are superior in filtering performance, smaller in physical size, and more flexible in application, compared to traditional passive filters using capacitors, inductors and/or resistors. However, the active filters are slightly inferior in cost and operating loss, compared to the passive filters, even at present [17]. Thus, in the case studied, while only the $5^{\text {th }}, 7^{\text {th }}$ and $11^{\text {th }}$ order harmonic components matter, together with the wide conducted interference spectrum, spreading from $1 \mathrm{kHz}$ to $12 \mathrm{MHz}$, a three phase filter F.LL.D3 series - AN/HN type, suitable for industrial environments, available in 440 Vac and $520 \mathrm{Vac}$ models was the option (Fig. 7.) [18].

The high performance, high voltage, three phase filter presents high attenuation characteristics, being especially designed for industrial based frequency inverters and motor drives. In the graph depicted in Fig. 8, one can observe the differential (dotted line) and the common 
mode (solid line) insertion loss in the frequency range from DC to $100 \mathrm{MHz}$.

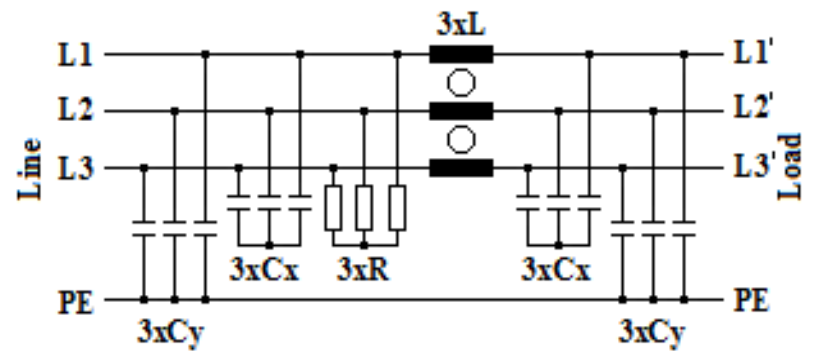

Fig. 7. Three phase passive EMI filter

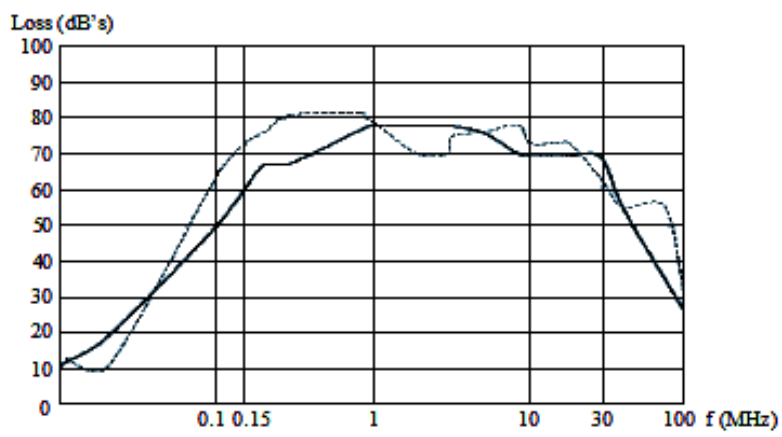

Fig. 8. Insertion loss

The 60-80 dB's value of the insertion loss in the frequency range from $100 \mathrm{kHz}$ to $30 \mathrm{MHz}$ which is of interest in the standard EN 50011 [19 ].

Tests according to standard EN 50011 are performed with $50 \Omega$ source and load impedances, matched with the characteristic impedance of most RF test equipments. However, in practical situations, $50 \Omega$ source and load impedances are complex and in general unknown, thus the predicted attenuation is in general optimistic, so one must take into account the prescriptions set by the standard EN 61800-3:2004/A1 [16], concerning EMC requirements and specific test methods for adjustable speed electrical power drive systems.

The chosen filter has the following rated values: $\mathrm{I}_{\mathrm{R}}=16 \mathrm{~A}$; $\Delta \mathrm{I}_{\mathrm{L}}=18 \mathrm{~mA} ; \mathrm{C}_{\mathrm{X}}=3 \times 4.4+3 \times 2.2 \mu \mathrm{F}$ (attenuate differential mode only); $\mathrm{C}_{\mathrm{Y}}=3 \times 10+3 \times 47 \mathrm{nF}$ (attenuate common mode interference); $\mathrm{L}=3 \times 5.2 \mathrm{mH}$ (the common mode choke $\mathrm{L}$, build in a symmetric configuration, allows high inductance values in a small volume, being wound on a ferrite core having a high $A_{L}$ value, which enhances the magnetic properties of the core, improving the insertion loss characteristics); $\mathrm{R}=3 \times 1 \mathrm{M} \Omega$; temperature range: $-25^{\circ} \mathrm{C}$ to $+85^{\circ} \mathrm{C}$;

The full inductance of each winding is available to attenuate common mode currents with respect to earth, but only the leakage inductance will attenuate differential mode interference.

Measurements were repeated after retrofitting the filter and the results are depicted in the Figs. 9 - 13.

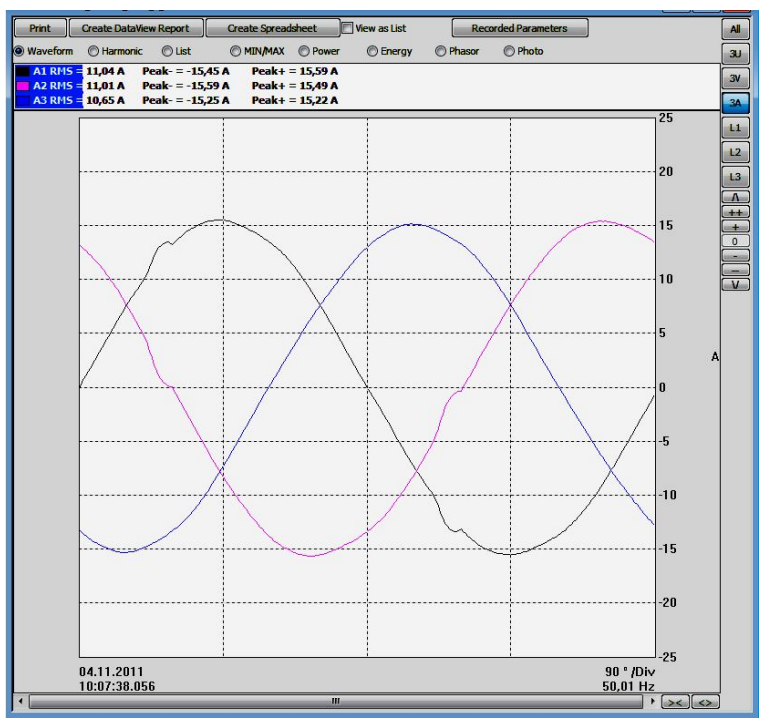

Fig. 9. Supply voltages of the ASD after EMI filtering

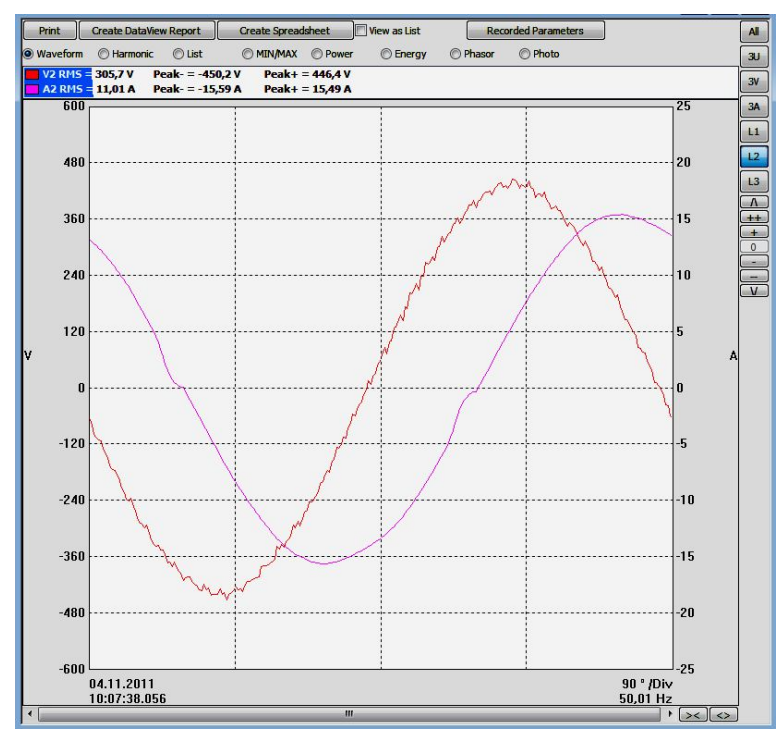

Fig. 10. Voltage supply and current drawn by line 2 of the ASD after EMI filtering

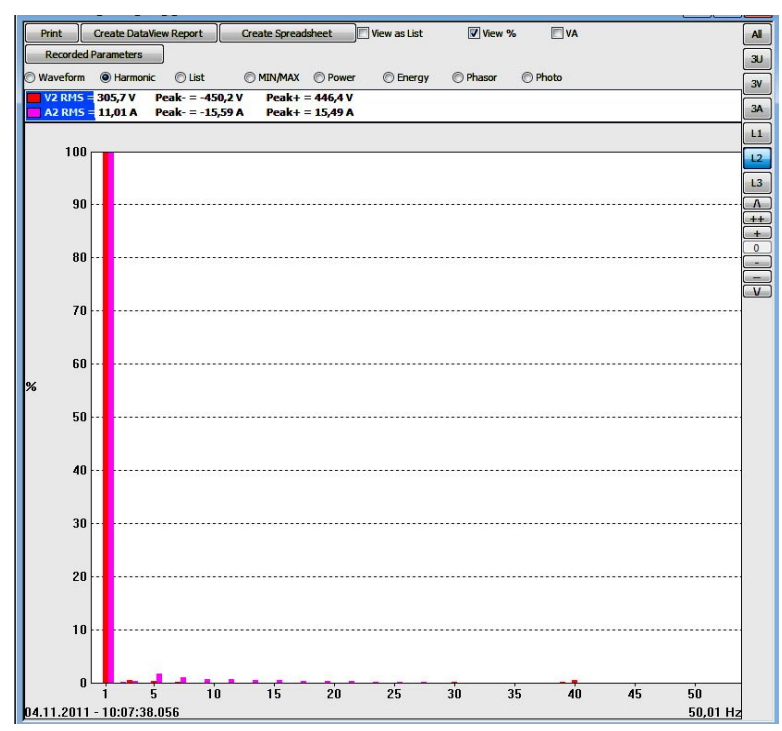

Fig. 11. THVD and TDID in line 2 of the ASD after EMI filtering 


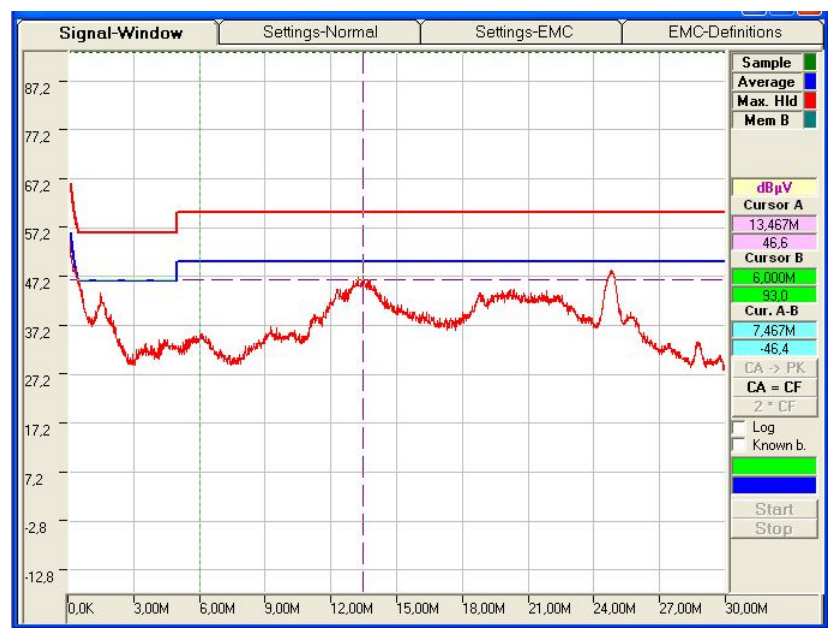

Fig. 12. Conducted interference generated by the ASD

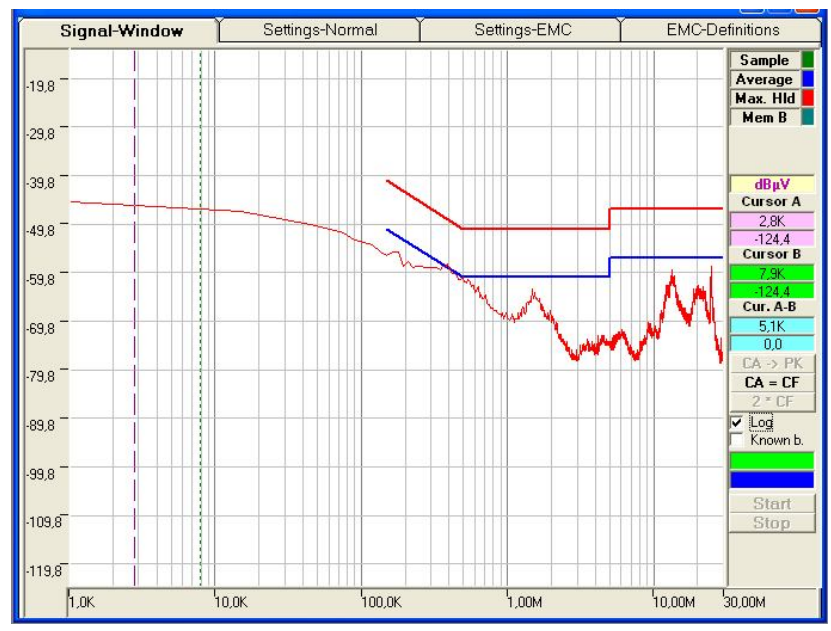

Fig. 13. Conducted interference generated by the ASD

The currents distortion greatly improved, their harmonic content being almost negligible, the conducted interferences lowered under the standard limits, but still a problem remains, namely the poor displacement power factor, determined by the lagging phase of the current. In the case studied it is more cost effective to perform a centralized solution for improving the displacement power factor, using dynamic capacitor banks on the point of power coupling (PCC), in the vicinity of the outputs of the transformer substations.

\section{Conclusions}

In the case study, since a large number of wells are driving heavy and high variable loads, the harmonics problem becomes compulsory, in order to improve energy efficiency. In the same time, due to environmental conditions, electromagnetic noise and perturbations are inherently present.

One simple, single solution was chosen in solving both problems, namely the use of a passive filtering method which is much more cost effective than the active filtering. Besides, it is well-known that active filtering introduces supplementary electromagnetic interferences, which in turn have to be cancelled.
Looking at the measurements performed in the oil field, one can conclude that the best method in improving the displacement power factor issue which still remains, is to provide dynamic capacitor banks in the vicinity of the output of the transformer substations.

Obviously an alternative method could be the use of tuned harmonic filters on every ASD, in order to obtain the necessary reactive power, but the resonances which might occur in the distribution feeders due to the large number of ASD connected to a PCC and the variability of the loads represented a major disadvantage for that the solution.

\section{References}

[1] Council of European Energy Regulators-Working Group on Quality of Electricity Supply (2001), Quality of electricity supply: Initial benchmarking on actual levels, standards and regulatory strategies.

[2]Math H. J. Bollen, Irene Yu-Hua Gu, Signal Processing Of Power Quality Disturbances, John Wiley \& Sons, Inc., 2006

[3] Montrose, M. I., Nakauchi, E. M., Testing for EMC Compliance -Approaches and Techniques, John Wiley \& Sons, Inc., 2004

[4] IEC/TR 61000-1-1(1992), Electromagnetic compatibility (EMC) - Part 1: General - Section 1: Application and interpretation of fundamental definitions and terms

[5] Sankaran, C., Power Quality, CRC Press LLC 2002

[6] Kusko, A., Thompson M.T., Power Quality in Electrical Systems, McGraw-Hill Companies, Inc., 2007

[7] Chattopadhyay, S., Mitra, M., Sengupta, S., Electric Power Quality, Springer Science+Business Media B.V. 2011

[8] Dugan, R.C., et all., Electrical Power Systems Quality, McGraw-Hill, 2004

[9] Arrillaga, J., Watson, N.R., Power System Harmonics, John Wiley \& Sons, Ltd, 2003

[10] European standard EN 50160, Voltage characteristics of electricity supplied by public distribution systems, CENELEC TC 8X, 2006

[11] Shepherd, W, Li Zhang, Power Converter Circuits, Marcel Dekker, Inc., 2004

[12] Wilamowski, B.M., Irwin, J. D., Power Electronics and Motor Drives, Taylor and Francis Group, LLC, 2011

[13] Mohan, N., Undeland, T.M., Robbins, W.P., Power Electronics Converters, Applications and Design, John Wiley \& Sons, Inc., 2003.

[14] http://www.chauvin-arnoux.com/produit/Famille detail.asp? idFam $=2058 \&$ idPole $=1$

[15] http://www.hameg.com/datasheets.0.html?\&no cache=1

[16] EN 61800-3:2004/A1:2012 Adjustable speed electrical power drive systems - Part 3: EMC requirements and specific test methods

[17] H. Akagi "Modern active filters and traditional passive filters" Bulletin of The Polish Academy of Sciences Technical Sciences, 2006, Vol. 54, No. 3, pp. 255-269

[18]http:/www.kemet.com/kemet/web/homepage/kechome.nsf/f ile/F.LL.D3\%20Series\%20AN,\%20HN\%20Type/

\$file/F9000 F.LL.D3 AN HN.pdf

[19] EN 55011:2007 Industrial, scientific and medical (ISM) radio-frequency equipment - Electromagnetic disturbance characteristics - Limits and methods of measurement 